\title{
Tranexamic acid reduces the need for allogenic red blood cell transfusions in patients undergoing total hip replacement
}

[L'acide tranexamique réduit les besoins de transfusion sanguine allogénique chez les patients devant subir une arthroplastie totale de la banche]

Erik Lemay MD FrCPC, ${ }^{*}$ Joanne Guay MD FRCPC, ${ }^{*}$ Christiane Côté RN, ${ }^{*}$ Alain Roy MD FrCPC†

Purpose: This prospective randomized double-blind trial evaluates the efficacy of tranexamic acid (TA) to decrease blood losses and red blood cell transfusions in patients undergoing primary unilateral total hip replacement (THR).

Methods: Forty ASA class I to III patients received either iv TA 10 $\mathrm{mg} \cdot \mathrm{kg}^{-1}$ bolus before surgery plus a I $\mathrm{mg} \cdot \mathrm{kg}^{-1} \cdot \mathrm{hr}^{-1}$ infusion until wound closure (Group TA) or a placebo (Group P). Red blood cell transfusions were administered according to a standardized protocol.

Results: One patient of Group P was excluded because of an erroneous diagnosis at enrollment. Total measured blood losses (Group TA: $1308 \pm 462$ mL vs Group P: $1469 \pm 405 \mathrm{~mL}$ ), preoperative hemoglobin levels (Group TA: $130.4 \pm 12.5 \mathrm{~g} \cdot \mathrm{L}^{-1}$ vs Group P: $\left.131.4 \pm 12.8 \mathrm{vs} g \cdot L^{-1}\right)$, and seven-day postoperative hemoglobin values (Group TA: $97.8 \pm 11.8 \mathrm{~g} \cdot \mathrm{L}^{-1}$ vs Group P: $102.9 \pm 12.2$ $\mathrm{g} \cdot \mathrm{L}^{-1}$ ) were similar. Autologous whole blood was available in five patients of Group P and seven patients of Group TA. Fewer patients in Group TA required red blood cells (Group TA: 6/20 vs Group P: 13/19; $P=0.026$ ) and allogenic red blood cell transfusions (Group TA: $0 / 20$ vs Group P: 8/19; $P=0.0012$ ). The median number of transfused unit per patient was also significantly less in patients of Group TA (0 unit) than in Group P (2 units; $P=0.03)$.

Conclusion: TA did not change measured blood losses but reduced red blood cell transfusion requirements in patients undergoing primary unilateral THR.

Objectif : Cette étude prospective, randomisée et en double aveugle évalue l'efficacité de l'acide tranexamique (AT) pour réduire le saignement et les transfusions sanguines des patients subissant une arthroplastie primaire unilatérale de la hanche.
Méthode : Quarante patients ASA I à III ont été divisés en deux groupes et ont reçu: $10 \mathrm{mg} \cdot \mathrm{kg}^{-1}$ d'AT à l'induction plus une perfusion de I $\mathrm{mg} \cdot \mathrm{kg}^{-1} \cdot \mathrm{h}^{-1}$ jusqu'à la fermeture de la plaie (Groupe AT) ou un placebo (Groupe $P$ ). Les transfusions sanguines étaient administrées selon un protocole prédéterminé.

Résultats : Un patient du Groupe $P$ a été exclu de l'analyse (diagnostic erroné). Les groupes sont comparables pour les pertes sanguines totales mesurées (1308 \pm 462 vs $1469 \pm 405$ mL), l'hémoglobine préopératoire $\left(130,4 \pm 12,5\right.$ vs 131,4 \pm 12,8. g. $\left.\mathrm{L}^{-1}\right)$ et postopératoire au jour sept (97,8 \pm II,8 vs 102,9 \pm 12,2 $\left.\mathrm{g} \cdot \mathrm{L}^{-1}\right)$ (groupes AT et $P$ respectivement). Le sang autologue était disponible pour cinq patients du Groupe $P$ et sept du Groupe AT. L'AT réduit le nombre de patients transfusés (6/20 vs /3/I9; $P=0,026)$, l'administration de sang homologue (0/20 vs $8 / 19 ; P=0,00 / 2)$ et le nombre d'unités transfusées par patient ( 0 vs 2; $P=0,03$ ).

Conclusion : L'AT ne réduit pas les pertes sanguines mesurées mais réduit les besoins en transfusions sanguines et l'administration de sang homologue chez les patients subissant une arthroplastie de la hanche.

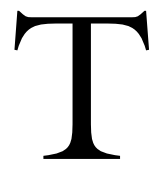
OTAL hip replacement (THR) is associated with high intraoperative and postoperative blood losses, which may result in need for allogenic blood transfusions in up to $97 \%$ of patients in the absence of blood conservation strategies. ${ }^{1}$ Lower transfusion trigger, preoperative autologous blood donation with or without erythropoietin, intraoperative red blood cell salvage, regional anesthe-

From the Departments of Anesthesiology, * and Surgery, $†$ Maisonneuve-Rosemont Hospital, University of Montreal, Montreal, Quebec, Canada.

Address correspondence to: Dr. Joanne Guay, Département d'anesthésie-réanimation, Hôpital Maisonneuve-Rosemont, 5415, boul.

l'Assomption, Montréal, Québec HIT 2M4, Canada. Phone: 514-252-3426; Fax: 514-252-3542; E-mail : joanne.guay@umontreal.ca

Accepted for publication April 17, 2003.

lst revision accepted June $25,2003$.

2nd revision accepted October 20, 2003.

Presented at the American Society of Anesthesiologists, San Francisco, October 2000.

This study was funded by a grant from the "Fonds de développement du département d'Anesthésiologie de l'université de Montréal". 
sia, controlled hypotension, and antifibrinolytic agents have all been recommended as useful means to decrease the need for allogenic transfusions. ${ }^{2-4}$ Among the antifibrinolytic agents, aprotinin was the first agent studied and has been reported to decrease total blood losses in primary and revised THR by approximately one fourth compared to placebo. ${ }^{5,6}$ However, aprotinin has been associated with some cases of anaphylactic reactions, especially when it is given repeatedly within a short period. ${ }^{7}$

Tranexamic acid (TA), a synthetic antifibrinolytic agent that is approximately seven to ten times more potent than aminocaproic acid, binds to the lysinebinding site of plasminogen and blocks the binding of plasminogen to the fibrin surface. ${ }^{8}$ Thus plasminogen activation is prevented and fibrinolysis is delayed. Therapeutic plasma concentrations of TA $(5-10$ $\mathrm{mg} \cdot \mathrm{L}^{-1}$ ) can be achieved with a bolus of $10 \mathrm{mg} \cdot \mathrm{kg}^{-1}$ iv followed by an infusion of $1 \mathrm{mg} \cdot \mathrm{kg}^{-1} \cdot \mathrm{hr}^{-1}$. ${ }^{9}$ Numerous studies have confirmed the efficacy of TA to reduce blood losses and transfusion requirements in total knee replacement (TKR). ${ }^{10-16}$ The aim of this study was to assess the efficacy of TA to reduce blood losses and blood transfusion requirements in patients undergoing THR.

\section{Methods}

This protocol was approved by the local Ethics Committee; written informed consent was obtained from all patients. Patients were eligible for this study if they were ASA class I to III and were undergoing primary THR. Patients were excluded if they had one of the following criteria: history of previous ipsilateral hip surgery, known or suspected allergy to medications used (TA, local anesthetics, midazolam, fentanyl, propofol, or dalteparin), anemia [hemoglobin $(\mathrm{Hb})<$ $115 \mathrm{~g} \cdot \mathrm{L}^{-1}$ for women, $\mathrm{Hb}<130 \mathrm{~g} \cdot \mathrm{L}^{-1}$ for men], inherited or acquired hemostatic diseases, abnormal coagulation screening tests (platelet count, prothrombin time, activated partial thromboplastin time), ingestion of aspirin or other nonsteroidal anti-inflammatory drugs within seven days of surgery, renal (serum creatinine $>$ two standard deviation for age) or hepatic insufficiency, pregnancy, history of deep venous thrombosis (DVT) or pulmonary embolism as well as a history of ocular pathology or ophthalmological procedure other than corrective lenses. A preoperative autologous donation of three units of blood was offered to all patients.

Patients were randomly allocated, with randomization in blocks of four, to receive either TA (Group TA) or a placebo (Group P). In Group TA, TA was given immediately before the surgery. After a test dose of 1
$\mathrm{mL}$, patients received a dose of $10 \mathrm{mg} \cdot \mathrm{kg}^{-1}$ iv followed by an infusion of $1 \mathrm{mg} \cdot \mathrm{kg}^{-1} \cdot \mathrm{hr}^{-1}$ until skin closure. Patients in Group P received an equivalent volume of physiologic saline. Both solutions were prepared by the pharmacist. Patient caregivers (nurses, residents, staff physicians), and the investigator collecting the data were blinded to the solution used.

All patients had spinal anesthesia with 12.5 to 15 $\mathrm{mg}$ of isobaric $0.5 \%$ bupivacaine for the surgery and intrathecal morphine 0.1 to $0.25 \mathrm{mg}$ for postoperative pain analgesia. Intraoperative sedation was tailored to individual needs using midazolam and fentanyl or propofol (maximum dose $50 \mu \mathrm{g} \cdot \mathrm{kg}^{-1} \cdot \mathrm{min}^{-1}$ ). Monitoring included five-lead electrocardiography (ECG), pulse oximetry, and blood pressure monitoring with a non-invasive cuff and radial artery cannula.

Before the surgery, a $\mathrm{Hb}$ transfusion trigger point was determined for each patient according to the following criteria: for men over $60 \mathrm{yr}$, women over $65 \mathrm{yr}$, and patients with a history of atherosclerotic disease, left ventricular dysfunction (ejection fraction $<35 \%$ ), severe pulmonary obstructive disease (forced expiratory volume in one second $<1.5 \mathrm{~L} \cdot \mathrm{min}^{-1}$ ), or ingestion of calcium channel blockers, the transfusion trigger was $90 \mathrm{~g} \cdot \mathrm{L}^{-1}$. For all other patients, the transfusion trigger was $70 \mathrm{~g} \cdot \mathrm{L}^{-1}$, but they could be reclassified to the higher trigger by the attending physician (anesthesiologist or physician in charge of the postoperative period) if they had signs of hemodynamic instability (heart rate $>120$ beats. $\mathrm{min}^{-1}$ or a systolic blood pressure decrease by $>20 \%$ of preoperative value) despite adequate volume replacement.

Intraoperative blood losses were measured by weighing sponges and suction drainage. Postoperative blood losses were assessed by measuring wound drainage until drains withdrawal $( \pm 36 \mathrm{hr})$. During surgery, measured blood losses were replaced with Ringer's lactate in a 3:1 ratio and/or with pentastarch $10 \%$ (maximum dose $1500 \mathrm{~mL}$ ) in a $1: 1$ ratio until $\mathrm{Hb}$ concentration fell below the transfusion trigger point. Thereafter, patients received allogenic packed red blood cells diluted in normal saline solution or, if available, autologous whole blood.

Factors known to influence intraoperative and postoperative blood losses were noted. These included approach and incision type, use of cemented or noncemented/hybrid prosthesis, length of surgery, mean arterial blood pressure maintained during surgery, and minimal core temperature achieved. Hemoglobin concentration and platelet count were measured preoperatively, in the post-anesthesia care unit (PACU) and on postoperative day one, four, and seven after surgery. In order to confirm that the patient had 
TABLE I General data

\begin{tabular}{|c|c|c|}
\hline & $\begin{array}{l}\text { Group P } \\
(n=19)\end{array}$ & $\begin{array}{l}\text { Group TA } \\
(n=20)\end{array}$ \\
\hline Age (yr) & $53.6 \pm 12.8$ & $59.7 \pm 10.3$ \\
\hline Gender (male/female) & $13 / 6$ & $12 / 8$ \\
\hline Weight (kg) & $74.7 \pm 14.1$ & $80.1 \pm 15.7$ \\
\hline Height $(\mathrm{cm})$ & $168.2 \pm 10.9$ & $169.8 \pm 8.4$ \\
\hline ASA physical status (I/II/III)) & $9 / 10 / 0$ & $6 / 12 / 2$ \\
\hline \multicolumn{3}{|l|}{ Preoperative screening coagulation tests } \\
\hline Platelet count $\left(\times 10^{9} \cdot \mathrm{L}^{-1}\right)$ & $246.4 \pm 64.9$ & $241.2 \pm 55.3$ \\
\hline Prothrombin time $(\mathrm{sec})$ & $10.4 \pm 0.71$ & $10.4 \pm 0.88$ \\
\hline International normalized ratio & $0.98 \pm 0.08$ & $0.99 \pm 0.11$ \\
\hline Activated partial thromboplastin time (sec) & $26.7 \pm 3.6$ & $28.2 \pm 4.4$ \\
\hline Surgical approach: anterolateral/posterior & $11 / 8$ & $12 / 8$ \\
\hline Cemented/noncemented prosthesis & $12 / 7$ & $15 / 5$ \\
\hline Length of surgery $(\mathrm{min})$ & $101.4 \pm 22.4$ & $106.6 \pm 26.4$ \\
\hline Body temperature in the PACU $\left({ }^{\circ} \mathrm{C}\right)^{*}$ & $35.2 \pm 0.5$ & $35.5 \pm 0.4$ \\
\hline Mean arterial blood pressure during surgery $(\mathrm{mmHg})$ & $75.8 \pm 9.2$ & $83.5 \pm 9.6$ \\
\hline Intraoperative crystalloids $(\mathrm{mL})$ & $3724 \pm 845.3$ & $3140 \pm 1322$ \\
\hline Intraoperative urine output (mL) & $450.8 \pm 285.4$ & $386.7 \pm 86.5$ \\
\hline
\end{tabular}

PACU $=$ postanesthesia care unit. All continuous values are expressed as mean \pm standard deviation. ${ }^{*} P=0.02$

TABLE II Blood losses, number of transfusions, and hemoglobin values

\begin{tabular}{lll}
\hline & $\begin{array}{l}\text { Group } P \\
(n=19)\end{array}$ & $\begin{array}{c}\text { Group TA } \\
(n=20)\end{array}$ \\
\hline $\begin{array}{l}\text { Intraoperative blood losses }(\mathrm{mL}) \\
\text { Postoperative blood losses }(\mathrm{mL})\end{array}$ & $911 \pm 363$ & $820.5 \pm 447.1$ \\
Total blood losses $(\mathrm{mL})$ & $580 \pm 290$ & $487 \pm 234$ \\
Hemoglobin values $\left(\mathrm{g} \cdot \mathrm{L}^{-1}\right)$ & $1469 \pm 405$ & $1308 \pm 462$ \\
$\quad$ Preoperative & $131.4 \pm 12.8$ & $130.4 \pm 12.5$ \\
PACU & $101.4 \pm 13.2$ & $106.8 \pm 15.1$ \\
Postoperative day one & $84.8 \pm 14.3$ & $92.5 \pm 12.1$ \\
Postoperative day four & $92.9 \pm 11.4$ & $93.0 \pm 13.4$ \\
Postoperative day seven & $102.9 \pm 12.2$ & $97.8 \pm 11.8$ \\
Transfusion trigger of $70 \mathrm{~g} \cdot \mathrm{L}^{-1}$ & $68.5 \pm 3.3$ & $85 *$ \\
Transfusion trigger of $90 \mathrm{~g} \cdot \mathrm{L}^{-1}$ & $75.3 \pm 3.1$ & $78.6 \pm 7.9$ \\
Hemoglobin value before administ blood unit $\left(g \cdot \mathrm{L}^{-1}\right)$ & & $5 / 15$ \\
Transfusion trigger $70 / 90 \mathrm{~g} \cdot \mathrm{L}^{-1}$ & $8 / 11$ & 7 \\
Predonated autologous blood & 5 & 6 \\
Administration of red blood cells $\dagger$ & 13 & 0 \\
Allogenic red blood cell transfusion $\ddagger$ & 8 & $0(0-3)$
\end{tabular}

All continuous values are expressed as mean \pm standard deviation; number of transfused units per patient is expressed as a median and range. $\mathrm{PACU}=$ postanesthesia care unit; ${ }^{*}$ One patient, $\dagger P=0.026, \ddagger P=0.0012, \$ P=0.03$

reached the transfusion trigger, $\mathrm{Hb}$ was measured also before the administration of any blood products.

Thromboprophylaxis included twice daily $s c$ dalteparin 5,000 U started on the day of surgery, anti-stasis stocking, and early postoperative mobilization. Clinical examination for DVT was performed daily. All patients underwent a Doppler ultrasound (Aloka-SSD 2000, Tokyo, Japan) of both inferior limbs between postoper- ative day five and ten or earlier if there was any clinical suspicion of DVT. Medical records were reviewed three months after the surgery to search for DVT that appeared later in the surgical follow-up. An ECG was obtained preoperatively, in the PACU, and daily for the first three days after the surgery. Changes in the ECG compatible with myocardial ischemia were recorded and patients were given appropriate treatment. 
The primary outcomes were intraoperative and total blood losses. Based on the study by Janssens et al., 20 patients per group would detect a $30 \%$ decrease in intraoperative and in total blood losses with a power of $80 \%$ and an $\alpha$ of 0.05 (one-tailed). ${ }^{5}$ Statistical analysis was performed using Student's t test, Chi square, Fisher's exact test, Mann-Whitney, one or two-way repeated measures ANOVA, and linear regression where appropriate. A $P$ value $<0.05$ was considered statistically significant.

\section{Results}

Forty patients were randomized in this study. One patient in Group P was excluded from the analysis because of an erroneous diagnosis at enrollment (THR plus osteotomy and acetabulum grafting for congenital dysplasia). The two groups were comparable for age, gender, weight, height, ASA physical status, length of surgery, surgical approach, use of cemented or noncemented/hybrid prosthesis and preoperative coagulation test results (Table I). Body core temperature at arrival in the PACU was slightly lower in Group P (Table I). No patient required conversion to general anesthesia. Mean arterial blood pressure maintained during surgery was similar between the two groups.

There was no difference between the two groups for intraoperative, postoperative, and total blood losses (Table II). The number of patients with a transfusion trigger of $70 \mathrm{~g} \cdot \mathrm{L}^{-1}$ vs $90 \mathrm{~g} \cdot \mathrm{L}^{-1}$ was not statistically different between the groups (Table II). However, the number of patients who required a red blood cell transfusion was higher in Group P $(13 / 19)$ than in Group TA $(6 / 20 ; P=0.026$; Figure 1 , Table II $)$. No patient in Group TA had an allogenic blood transfusion compared to eight patients in Group $\mathrm{P}(P=0.0012)$. The median number of blood units transfused per patient was also higher in Group P ( $P=0.029$; Table II). There was no correlation between minimal body temperature achieved at arrival in the PACU (range $34.5-36.6^{\circ} \mathrm{C}$ ) and intraoperative (range 200 to $2000 \mathrm{~mL} ; \mathrm{r}^{2}=0.02, P=0.42$ ) or total blood losses (range 507 to $2428 \mathrm{~mL} ; \mathrm{r}^{2}=0.05$; $P=0.17$; Figure 2). Hemoglobin concentrations measured preoperatively, in the PACU and at postoperative days one, four and seven were comparable between the groups (Table II). Mean $\mathrm{Hb}$ before the first transfusion was $70.0 \pm 8 \mathrm{~g} \cdot \mathrm{L}^{-1}$ for patients with a transfusion trigger of $70 \mathrm{~g} \cdot \mathrm{L}^{-1}$ (regardless of the group) and $77 \pm 9 \mathrm{~g} \cdot \mathrm{L}^{-1}$ for patients with a transfusion trigger of $90 \mathrm{~g} \cdot \mathrm{L}^{-1}$. The amount of crystalloid solution used for fluid replacement was comparable between the groups intraoperatively (Table I) and for the first $24 \mathrm{hr}$ after the surgery.

There were no thromboembolic complications detected in either group during hospitalization and

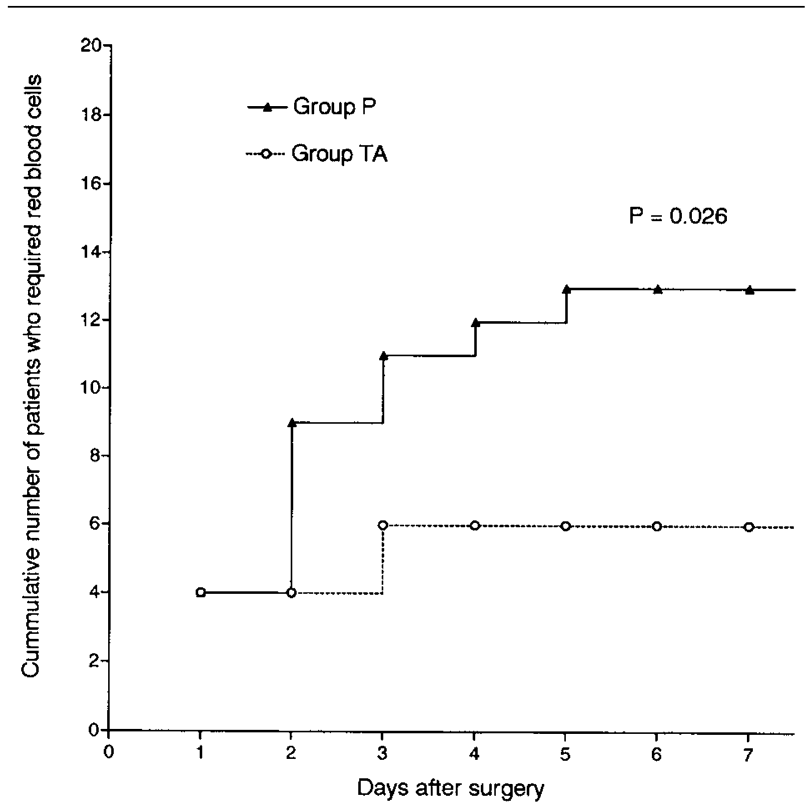

FIGURE 1 Cumulative number of patients who received red blood cells (autologous whole blood or allogenic packed red blood cells). Group P = placebo; Group TA = tranexamic acid. The total number of patients is significantly lower in Group TA than in Group $\mathrm{P}(P=0.026)$.

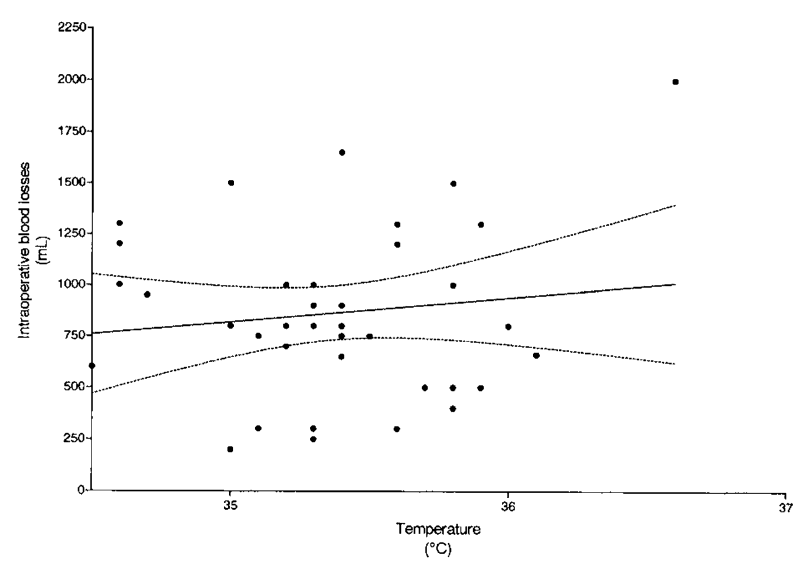

FIGURE 2 Intraoperative blood losses $p s$ central core temperature upon arrival in the postanesthesic care unit. Linear regression: slope and confidence interval $95 \%\left(r^{2}=0.02, P=0.42\right)$. 
review of medical records failed to reveal any at three months after the surgery. Data were available for all patients. One patient in Group P suffered from a brief respiratory arrest in the PACU. She had a delay in volume replacement from early postoperative blood losses. Her ECG showed ST elevation in leads V2 and V3 in the PACU but returned to normal by the next morning. Blood CK-MB fraction and troponin values stayed within normal limits. Another patient of Group P was reintubated in the PACU for delirium from unrecognized alcohol withdrawal. His ECG showed transitory ST segment depression on postoperative day two. One patient in Group TA had ECG changes consisting of T waves inversion in the lateral leads in the PACU and on postoperative days one and two. On day three, his ECG returned to preoperative status (non-specific repolarization modifications).

\section{Discussion}

TA did not decrease intraoperative or total blood losses; however, it reduced the number of patients who needed red blood cell transfusions compared to placebo (relative risk reduction 56.2\%; 95\% confidence interval $8.5 \%, 79 \%$ ). The number of packed red blood cell units transfused per patient was also significantly lower in the TA group ( 0 vs $2 \mathrm{U}$ ) and no patients of Group TA required allogenic red blood cells.

So far, three studies have examined the efficacy of TA to reduce blood losses and blood transfusions during THR. ${ }^{17-19}$ In the first study, patients were randomized to receive placebo or two iv doses of TA $10 \mathrm{mg} \cdot \mathrm{kg}^{-1}$ after surgery. ${ }^{17}$ The investigators found a $62 \%$ relative risk reduction in the number of patients who required a red blood cell transfusion with TA (4/19) compared to placebo $(11 / 20)$, but no difference in measured blood losses. In the second study, patients were randomized to receive placebo or one dose of TA $10 \mathrm{mg} \cdot \mathrm{kg}^{-1}$ iv just before the surgery. There was a $24 \%$ decrease in measured blood losses $(P=0.01)$ but the decrease in the total number of units transfused ( 5 vs 13 ) was not statistically significant. ${ }^{19}$ In the third study, patients were randomized to receive placebo or two $i v$ doses of TA 10 $\mathrm{mg} \cdot \mathrm{kg}^{-1}$ (first dose just before the surgery) plus an infusion of $1 \mathrm{mg} \cdot \mathrm{kg}^{-1} \cdot \mathrm{hr}^{-1}$ until skin closure. ${ }^{18}$ The authors reported a $36 \%$ decrease in measured blood losses. The number of allogenic red blood cell units transfused was not decreased but, in that study, all patients had autologous blood predonation (two units on two occasions within four weeks) plus intraoperative autotransfusion.

From these three studies and the results of the present investigation, TA does not appear to help in reducing allogenic blood transfusions in patients without anemia, who undergo THR, if at least two units of autologous whole blood are donated before surgery and intraoperative autotransfusion is used. If not, TA is helpful in reducing the number of patients who will require allogenic red blood cells. A preoperative dose of $10 \mathrm{mg} \cdot \mathrm{kg}^{-1}$ iv is probably sufficient to obtain the maximal effect. Adding an intraoperative infusion of 1 $\mathrm{mg} \cdot \mathrm{kg}^{-1} \cdot \mathrm{hr}^{-1}$, as in the present study, does not seem to add any extra benefit. From the present study and the available literature on TA in TKR and THR, the administration of TA does not seem to increase the risks of inducing thromboembolic phenomenons (total incidence of $15 / 305(4.3 \%)$ with TA vs $22 / 345$ (7.2\%) with placebo). ${ }^{10-19}$

In the present study, despite a $56.2 \%$ relative risk reduction in the number of transfused patients; there was no difference in measured blood losses. In order not to increase the risks of prosthesis infection of patients undergoing THR and TKR, surgical drains are now either rapidly removed or even avoided. This practice may lead to diffuse hemorrhagic suffusion around the surgical wound. Changes in $\mathrm{Hb}$ level indicate that blood losses of patients undergoing TKR and THR could be as much as $1000 \mathrm{~mL}$ over those measured by weighing sponges plus intra- and postoperative drainage. ${ }^{20}$ These hidden blood losses might explain the apparent discrepancy between the lack of difference in measured blood losses and the reduction of patients requiring a red blood cell transfusion with TA.

At arrival in the PACU, patients in Group TA had a central core temperature of $0.3^{\circ} \mathrm{C}$ higher than those of Group P. The influence of mild hypothermia on blood losses of patients undergoing THR is controversial, but we do not think that this difference could have influenced our results for the following reasons: ${ }^{21,22}$ first, the difference in body temperature observed between our two groups of patients was too small to have any influence on bleeding since studies that have demonstrated higher blood losses in mildly hypothermic patients reported a decrease in central core temperature of $1.6^{\circ} \mathrm{C}$ in patients with higher blood losses; $;^{22}$ second, in the range of central core temperature observed in our patients, there was no correlation between temperature at arrival in the PACU and intraoperative or total blood losses (Figure 2).

It is highly probable that TA reduces blood losses by delaying fibrinolysis. Enhanced fibrinolysis has been demonstrated during TKR and it is believed to be due to tourniquet use. ${ }^{15}$ However, Ekbäck et al. also demonstrated a lower increase in postoperative Ddimers with the administration of TA during THR, suggesting that at least part of the process may be due to the orthopedic surgery itself and/or the cement or prosthesis implantation. ${ }^{18}$ 
Adherence to protocol for transfusion criteria was suboptimal. Though the predetermined transfusion trigger was observed by clinicians, once the decision to give blood products was made, the attending physician appeared to target a $\mathrm{Hb}$ level around $100 \mathrm{~g} \cdot \mathrm{L}^{-1}$ before discharge. Patients of both groups received a "fixed amount of red blood cells" resulting in final $\mathrm{Hb}$ levels exceeding the recommended levels suggested by clinical practice guidelines. ${ }^{2}$ Other investigators have also encountered the same problem. ${ }^{23}$ In a recent multicentre study evaluating the efficacy of a $\mathrm{Hb}$ solution to reduce allogenic blood transfusions, attending physicians adopted the same attitude and, mean $\mathrm{Hb}$ level at discharge was also $100 \mathrm{~g} \cdot \mathrm{L}^{-1}$. Thus, though we now have many strategies to reduce the perioperative administration of allogenic blood transfusions, the battle to eliminate allogenic blood products from the surgical setting is far from over. Further education of all personnel involved in postoperative care will be needed to achieve this important goal.

In conclusion, for patients undergoing primary unilateral THR, TA did not change intraoperative or total measured blood losses but reduced the number of patients who required red blood cell transfusions and the number of transfused units of blood per patient.

\section{References}

1 McSwiney MM, O'Farrell D, Joshi GP, McCarroll SM. Blood transfusion in total hip arthroplasty: guidelines to eliminate overtransfusion. Can J Anaesth 1993; 40: 222-6.

2 Anonymous. Practice guidelines for blood component therapy: a report by the American Society of Anesthesiologists Task Force on Blood Component Therapy. Anesthesiology 1996; 84: 732-47.

3 Spahn DR, Casutt M. Eliminating blood transfusions: new aspects and perspectives. Anesthesiology 2000; 93: 242-55.

4 Sharrock NE, Mineo R, Urquhart B, Salvati EA. The effect of two levels of hypotension on intraoperative blood loss during total hip arthroplasty performed under lumbar epidural anesthesia. Anesth Analg 1993; 76: 580-4.

5 Janssens $M$, Joris J, David J, Lemaire R, Lamy M. Highdose aprotinin reduces blood loss in patients undergoing total hip replacement surgery. Anesthesiology 1994; 80: 23-9.

6 Murkin JM, Shannon NA, Bourne RB, Rorabeck CH, Cruickshank M, Wyile G. Aprotinin decreases blood loss in patients undergoing revision or bilateral total hip arthroplasty. Anesth Analg 1995; 80: 343-8.

7 Dietrich W, Spuath P, Zuublsdorf M, et al. Anaphylactic reactions to aprotinin reexposure in cardiac surgery: relation to antiaprotinin immunoglobulin $\mathrm{G}$ and $\mathrm{E}$ antibodies. Anesthesiology 2001; 95: 64-71.

8 Hoylaerts M, Lijnen HR, Collen D. Studies on the mechanism of antifibrinolytic action of tranexamic acid. Biochim Biophys Acta 1981; 673: 75-85.

9 Horrow JC, VanRiper DF, Strong MD, Grunewald KE, Parmet JL. The dose-response relationship of tranexamic acid. Anesthesiology 1995; 82: 383-92.

10 Benoni $G$, Carlsson A, Petersson C, Fredin H. Does tranexamic acid reduce blood loss in knee arthroplasty? Am J Knee Surg 1995; 8: 88-92.

11 Benoni $G$, Fredin $H$. Fibrinolytic inhibition with tranexamic acid reduces blood loss and blood transfusion after knee arthroplasty. A prospective, randomised, double-blind study of 86 patients. J Bone Joint Surg (Br) 1996; 78-B: 434-40.

12 Hiippala S, Strid L, Wennerstrand $M$, et al. Tranexamic acid (Cyklokapron) reduces perioperative blood loss associated with total knee arthroplasty. Br J Anaesth 1995; 74: 534-7.

13 Howes JP, Sharma V, Cohen AT. Tranexamic acid reduces blood loss after knee arthroplasty (Letter). J Bone Joint Surg (Br) 1996; 78-B: 995-6.

14 Hiippala ST, Strid LJ, Wennerstrand MI, et al. Tranexamic acid radically decreases blood loss and transfusions associated with total knee arthroplasty. Anesth Analg 1997; 84: 839-44.

15 Jansen AJ, Andreica S, Claeys M, D'Haese J, Camu F, Jochmans $K$. Use of tranexamic acid for an effective blood conservation strategy after total knee arthroplasty. Br J Anaesth 1999; 83: 596-601.

16 Zohar E, Fredman B, Ellis M, Luban I, Stern A, Jedeikin $R$. A comparative study of the postoperative allogeneic blood-sparing effect of tranexamic acid versus acute normovolemic hemodilution after total knee replacement. Anesth Analg 1999; 89: 1382-7.

17 Benoni G, Lethagen S, Nilsson P, Fredin H. Tranexamic acid, given at the end of the operation, does not reduce postoperative blood loss in hip arthroplasty. Acta Orthop Scand 2000; 71: 250-4.

18 Ekback G, Axelsson K, Ryttberg L, et al. Tranexamic acid reduces blood loss in total hip replacement surgery. Anesth Analg 2000; 91: 1124-30.

19 Benoni $G$, Fredin H, Knebel R, Nilsson P. Blood conservation with tranexamic acid in total hip arthroplasty. A randomized, double-blind study in 40 primary operations. Acta Orthop Scand 2001; 72: 442-8.

20 Samama CM, Langeron $O$, Rosencher $N$, et al. Aprotinin versus placebo in major orthopedic surgery: a randomized, double-blinded, dose-ranging study. The Hemorragies et Aprotinine en Chirurgie Orthopédique Lourde Study Group. Anesth Analg 2002; 95: 287-93. 
21 Johansson T, Lisander B, Ivarsson I. Mild hypothermia does not increase blood loss during total hip arthroplasty. Acta Anaesthesiol Scand 1999; 43: 1005-10.

22 Schmied H, Kurz A, Sessler DI, Kozek S, Reiter A. Mild hypothermia increases blood loss and transfusion requirements during total hip arthroplasty. Lancet 1996; 347: 289-92.

23 Lamy ML, Daily EK, Brichant JF, et al. Randomized trial of diaspirin cross-linked hemoglobin solution as an alternative to blood transfusion after cardiac surgery. Anesthesiology 2000; 92: 646-56. 